\title{
REDISTRIBUTION OF ACETYLCHOLINE RECEPTORS ON DEVELOPING RAT MYOTUBES ${ }^{1}$
}

\author{
LEA ZISKIND-CONHAIM, ${ }^{2}$ IRIS GEFFEN, ${ }^{3}$ AND ZACH W. HALL

\begin{abstract}
Division of Neurobiology, Department of Physiology S-762, University of California School of Medicine,
\end{abstract} \\ San Francisco, California 94143
}

Received June 10, 1983; Revised January 30, 1984; Accepted February 7, 1984

\begin{abstract}
The mechanism of formation of acetylcholine receptor (AChR) clusters at developing mammalian endplates was investigated in vitro, using intercostal muscles from embryonic rats. The muscles were explanted in organ culture with the spinal cord attached, as described previously (7iskind-Conhaim, I., and M. J. Dennis (1981) Dev. Biol. 85: 243-251). AChRs on the myofibers were labeled with [ $\left.{ }^{125} \mathrm{I}\right]-\alpha$-bungarotoxin shortly before clusters appeared and subsequently were cultured in unlabeled toxin for 1 day. Autoradiography of the cultured fibers demonstrated the presence of labeled clusters of AChRs indicating that the AChRs in the newly formed clusters arise from AChRs that had previously been uniformly distributed on the muscle surface.
\end{abstract}

When nerves first make functional contact with myotubes during the development of the neuromuscular junction, acetylcholine receptors (AChRs) are diffusely distributed on the surface of the myotubes (Dennis et al., 1981). One to 2 days after neuromuscular transmission is established, a high-density cluster of AChRs appears in the myotube membrane at the site of nerve contact; the appearance of this cluster is one of the first detectable signs of synaptic differentiation (Dennis, 1981). In dissociated nerve and muscle cultures from Xenopus, such clusters have been shown to arise, at least in part, by redistribution of $\mathrm{AChRs}$ that exist on the myotubes prior to their innervation (Anderson et al., 1977). We have investigated the origin of the AChR clusters at mammalian endplates using an organ culture system of embryonic rat muscle in which the time course of differentiation closely parallels that seen in vivo (Ziskind-Conhaim and Dennis, 1981). We have labeled AChRs in this muscle with $\left[{ }^{125} \mathrm{I}\right]-\alpha$-bungarotoxin $\left(\left[{ }^{125} \mathrm{I}\right]-\alpha\right.$-BuTx $)$ prior to cluster formation and have examined quantitatively the redistribution of the labeled AChRs. Our results demonstrate that a significant fraction of AChRs in the clusters formed in vitro were previously diffusely distributed.

\section{Materials and Methods}

Segments of thoracic body wall, including intercostal muscles, ribs, and spinal cord, were taken from 15-day embryonic rats and maintained

${ }^{1}$ This work was supported by grants from the National Institutes of Health and the Muscular Dystrophy Association. We thank Dr. William Betz for encouragement, Ms. Nicole Robitaille-Giguere for preparing $\left[{ }^{125} \mathrm{I}\right]-\alpha$-bungarotoxin, Ms. Liz Neville and Ms. Kemet Wefer for help with the manuscript, and Drs. Roy Black, Gary Reiness, James Hudspeth, and Chauncey Bowers for their comments on the manuscript.

${ }^{2}$ To whom correspondence should be addressed.

${ }^{3}$ Present address: Department of Biochemistry, Albert Einstein College of Medicine, Bronx, NY 10461. in organ culture as described by Ziskind-Conhaim and Dennis (1981). Previous experiments had established that, at 15 days of gestation, AChRs are uniformly distributed along $90 \%$ of the intercostal muscle fibers and that a single AChR cluster appears at the site of nerve contact after 1 day in organ culture (Ziskind-Conhaim and Bennett, 1982). This cluster appears within 1 day only when the muscle is cultured with spinal cord, and its time of appearance coincides with the normal time (16 days) of cluster appearance in vivo (Bevan and Steinbach, 1977; Harris, 1981).

AChRs were labeled in our experiments according to four protocols. To determine the total number and distribution of AChRs, intercostal muscles from 15-day-old rat embryos were labeled directly with $\left[{ }^{125} \mathbf{I}\right]$ $\alpha$-BuTx before (15) and after $(15+1)$ being cultured for 1 day in normal medium. To label separately AChRs that were present at the time of culture and those that appeared later, we labeled 15-day muscles with $\left[{ }^{125} \mathrm{I}\right]-\alpha$-BuTx and subsequently cultured them in unlabeled toxin $(15+1$, prelabeled), or incubated them in unlabeled toxin followed by culture in medium containing labeled toxin $(15+1$, postlabeled).

AChRs were labeled by placing segments of muscle-spinal cord on a rocking platform and incubating them with $2 \mu \mathrm{g} / \mathrm{ml}$ of $\left[{ }^{125} \mathrm{I}\right]-\alpha-B u T x$ for $2 \mathrm{hr}$ at $31^{\circ} \mathrm{C}$, the highest temperature at which the explants survive in vitro (Ziskind-Conhaim and Dennis, 1981). Under these conditions AChRs were assumed to be quantitatively labeled, since in separate experiments incubation of 15-day explants with $0.5 \mu \mathrm{g} / \mathrm{ml}$ of unlabeled $\alpha$-BuTx for $1 \mathrm{hr}$ completely blocked the depolarizing response to 10 mM carbamylcholine ejected locally from a micropipette. Following incubation with labeled toxin, muscles were thoroughly washed by changing the medium every $10 \mathrm{~min}$ for the first $30 \mathrm{~min}$ and every 30 min for the next $3 \mathrm{hr}$. At the end of the washout period, the amount of radioactivity in the medium was less than $0.5 \%$ of that originally present. In experiments in which muscles were maintained in organ culture after labeling $(15+1$, prelabeled), muscle-spinal cord explants were incubated at $31^{\circ} \mathrm{C}$ for $22 \mathrm{hr}$ in medium containing $10 \mu \mathrm{g} / \mathrm{ml}$ of unlabeled $\alpha$-BuTx. The unlabeled toxin, whose concentration was 5fold higher than that used to label the AChRs, prevented rebinding of any released $\left[{ }^{12 b} \mathrm{I}\right]-\alpha$-BuTx to newly synthesized receptors. In the experiments designed to label $\mathrm{AChRs}$ that appeared during culture (15 +1 , postlabeled), muscles were incubated in $10 \mu \mathrm{g} / \mathrm{ml}$ of unlabeled toxin for $2 \mathrm{hr}$, washed as described above, and then cultured for $22 \mathrm{hr}$ in medium containing $2 \mu \mathrm{g} / \mathrm{ml}$ of $\left[{ }^{125} \mathrm{I}\right]-\alpha-B u T x$. After each protocol, 
the muscles were fixed, dissociated to single fibers, and prepared for autoradiography as previously described (Ziskind-Conhaim and Bennett, 1982). The specific activity of the toxin varied between 95 and $160 \mathrm{cpm} / \mathrm{fmol}$, and the emulsion was exposed for 3 to 7 days. Grain density determined on emulsion outside the fibers was taken as background and was subtracted from all values determined over the fibers. For calculating the number of AChRs from the rate of grain production we assumed that $3 \mathrm{cpm}$ are equivalent to $1 \mathrm{grain} / \mathrm{min}$ (Burden, 1977).

\section{Results}

Autoradiography of muscle fibers that were labeled immediately after being taken from 15-day embryonic muscles confirmed that AChRs in these fibers were uniformly distributed and established their density at $218 \pm 5$ (mean $\pm \mathrm{SE}, n=36)$ toxin-binding sites $/ \mu \mathrm{m}^{2}$. This is comparable to the value of 157 sites $/ \mu \mathrm{m}^{2}$ measured by Bevan and Steinbach (1977) in 15-day embryonic sternomastoid muscle fibers. At day 15 clusters were seen on $12 \%$ of the intercostal muscle fibers. After 15-day muscles were cultured in normal culture medium for 1 day (15 $+1)$, the density of AChRs in the extrajunctional membrane was approximately the same as at day $15\left(243 \pm 12\right.$ sites $/ \mu \mathrm{m}^{2}$, $n=59$ ); in addition, clusters were formed on $90 \%$ of fibers. $\mathrm{AChR}$ density in the clusters was approximately 5 -fold higher than the extrajunctional density (Table I) and was similar to that seen in vivo (Bevan and Steinbach, 1977). In most fibers, no more than one cluster occurred per fiber. Calculation of the total number of AChRs (assuming the muscle fiber is a collapsed cylinder of length $200 \mu \mathrm{m}$ and diameter $4 \mu \mathrm{m}$, and one cluster per fiber with an average length of $16 \mu \mathrm{m}$ ) indicated that the number of AChRs per muscle fiber increased by $24 \%$ during the period of culture (Table I). Because the extrajunctional density increased by only $11 \%$, the remaining $13 \%$ increase must be due to the clustered AChRs.

We then examined AChR redistribution by labeling the receptors in day-15 muscle-spinal cord explants with $\left[{ }^{125} \mathrm{I}\right]-\alpha$ $\mathrm{BuTx}$ and subsequently culturing them for $22 \mathrm{hr}$ in the presence of unlabeled toxin. Autoradiography of the pulse-labeled fibers showed that $84 \%$ had an AChR cluster. These were usually in the center of the fibers (Fig. 1). The density of AChRs in these clusters was $1123 \pm 74 / \mu \mathrm{m}^{2}(n=41$; Table I $)$, a value that is $87 \%$ of that seen in control muscles $(15+1)$ which were labeled after culturing for 1 day. The mean size of the clusters in 15day muscles that were labeled and then cultured $(15+1$, prelabeled), and in muscles that were labeled after culturing $(15+1)$, was the same $(16.2 \pm 0.7 \mu \mathrm{m}$ and $16.0 \pm 0.5 \mu \mathrm{m}$, respectively). Thus, the clusters induced by the nerve in the cultured explants appear to have been formed in part from AChRs that were diffusely distributed on the surface of the muscle fibers at the time of labeling.

A comparison of the density of AChRs in the extrajunctional membrane of labeled 15-day fibers and pulse-labeled muscles cultured for 1 day $(15+1$, prelabeled) showed that the extra-



Figure 1. Autoradiography of single muscle fibers from rat embryos labeled with $\left[{ }^{125} \mathrm{I}\right]-\alpha$-BuTx. The fibers were derived from a 15 -day embryonic muscle (15), from a 15-day muscle cultured for $22 \mathrm{hr}$ in normal medium $(15+1)$, and from a muscle that was pulse labeled with [ $\left.{ }^{125} \mathrm{I}\right]-\alpha$-BuTx and subsequently cultured for $22 \mathrm{hr}$ in unlabeled $\alpha$ BuTx $(15+1$, pre.). The specific activity of the toxin was $137 \mathrm{cpm} /$ fmol, and the emulsion was exposed for 5 days. The distribution of AChRs on the $15+1$ and $15+1$, prelabeled fibers is similar. Scale bar, $20 \mu \mathrm{m}$.

\section{TABLE I}

The redistribution of $\left[{ }^{125} I\right] \alpha$-BuTx binding sites in embryonic muscle during explantation in organ culture

Intercostal muscles with spinal cord attached from 15-day rat embryos were cultured with and without $\alpha$-BuTx in the medium. Muscles were labeled with [ $\left.{ }^{125} \mathrm{I}\right]-\alpha$-BuTx before (15) and after $(15+1)$ culture for $22 \mathrm{hr}$ in normal medium as described in the text. Muscles were also labeled with $\left[{ }^{125} \mathrm{I}\right]-\alpha$-BuTx and subsequently cultured in unlabeled toxin $(15+1$, prelabeled) or were incubated with unlabeled toxin and subsequently cultured in $\left[{ }^{125} \mathrm{I}\right]-\alpha$-BuTx $(15+1$, postlabeled). The procedure for autoradiography on single fibers was described by Ziskind-Conhaim and Bennett (1982). For calculating the total number of receptors we measured grain density only on fibers at least $200 \mu \mathrm{m}$ long. We assumed that the fibers are collapsed cylinders of length $200 \mu \mathrm{m}$ and diameter $4 \mu \mathrm{m}$ and a rectangle cluster $16 \mu \mathrm{m}$ long and $4 \mu \mathrm{m}$ wide. The increase in the size of the muscle fibers during the time in organ culture is smaller than in vivo (Ziskind-Conhaim and Dennis, 1981) and for these calculations is negligible.

\begin{tabular}{|c|c|c|c|c|}
\hline Muscle & \multicolumn{2}{|c|}{$\begin{array}{c}\text { Bound }\left[{ }^{125} \mathrm{I}\right]-\alpha-\mathrm{BuTx} \\
\left.\text { Density (molecules } / \mu \mathrm{m}^{2}\right)\end{array}$} & $\begin{array}{c}\text { Total Number } \\
\left(\text { molecules/fiber } \times \quad 10^{5}\right)\end{array}$ & $\begin{array}{c}\text { Percentage } \\
\text { Change }\end{array}$ \\
\hline 15 & & $218 \pm 5 \quad(n=36 / 4)^{a}$ & 5.48 & 100 \\
\hline $15+1$, prelabeled & $1123 \pm 74$ & $153 \pm 10(n=41 / 4)$ & 4.46 & 81 \\
\hline $15+1$, postlabeled & $1241 \pm 82$ & $239 \pm 20(n=24 / 3)$ & 6.65 & 121 \\
\hline
\end{tabular}

\footnotetext{
${ }^{a}$ Mean \pm standard error; $n=$ number of fibers per number of experiments.
} 
junctional density of labeled AChRs declined approximately $30 \%$ during the culture period. This decline reflects both $\mathrm{AChR}$ turnover and loss of extrajunctional AChRs to the newly formed clusters. We estimated the extent of receptor turnover during the culture period by calculating the total number of labeled AChRs (clustered and unclustered) as described above and found only $19 \%$ loss of toxin-receptor complex from the muscles during culture (Table I). The increased metabolic stability of the receptors in our experiments compared to extrajunctional receptors in vivo (Reiness and Weinberg, 1981) presumably is due to lower temperature of explant incubation $\left(31^{\circ} \mathrm{C}\right)$ and is in good agreement with the rate of degradation of AChRs at $30^{\circ} \mathrm{C}$ seen in chick primary muscle culture (Devreotes and Fambrough, 1975). The total number of AChRs in the clusters of pulse-labeled muscles $\left(15+1\right.$, prelabeled) was $7.18 \times 10^{4}$ (assuming the cluster is a rectangle of $16 \mu \mathrm{m}$ length and $4 \mu \mathrm{m}$ width), which constituted $13 \%$ of the total number of receptors detected at day 15 (Table I) and $16 \%$ of the total number of receptors in these fibers. In control muscles $(15+1)$ the clustered AChRs account for $12 \%$ of the total number of receptors.

Because unlabeled muscles undergo a $24 \%$ increase in AChR number during the culture period (cf. (15) and (15+1) in Table I), new AChRs must be added during this time. To determine the disposition of the newly added AChRs, we blocked all AChRs in 15-day muscles with unlabeled $\alpha$-BuTx, and, after washing, subsequently incubated the muscles for $22 \mathrm{hr}$ in radioactive $\alpha$-BuTx $(15+1$, postlabeled). Autoradiography of these fibers showed both diffuse labeling and labeling of clusters. Thus, in addition to pre-existing diffuse AChRs, newly formed clusters also contained AChRs that were added during the culture period.

\section{Discussion}

The most important result of our experiments is the demonstration that $\mathrm{AChR}$ clusters that appear at developing endplates in mammalian muscle arise in part from the redistribution of pre-existing, diffusely distributed AChRs. AChRs labeled at day 15 , when most muscle fibers do not have $\mathrm{AChR}$ clusters, aggregate to form clusters in vitro that contain labeled $\mathrm{AChRs}$. Nerves have been shown to cause a redistribution of AChRs on cultured Xenopus myocytes (Anderson and Cohen, 1977), but such an effect has not been reported previously for mammalian muscle cells. When cultured with rat myotubes, cells in spinal cord explants make functional synapses with the myotubes but do not induce clustering of $\mathrm{AChRs}$ at synaptic sites (Kidokoro and Patrick, 1978; Kidokoro, 1980); neuroblastoma cells, in contrast, induce high $\mathrm{ACh}$ sensitivity in rat myotubes at sites of contact but do not form functional synapses (Harris et al., 1971). Brain extracts have also been shown to increase the number of receptor clusters at random sites along mouse and rat myotubes (Christian et al., 1978; Salpeter et al., 1982). However, AChR clustering at functional synaptic sites does occur in vitro, in the explanted rib cage-spinal cord preparation used in these experiments (Ziskind-Conhaim and Dennis, 1981). In the explanted thoracic body wall, the normal topographic relations of nerve and muscle are maintained, and differentiation of the endplate occurs with a time course that closely mimics that seen in vivo. The clusters that are formed occur only at sites of nerve-muscle contact and are of comparable size to those seen in vivo (Ziskind-Conhaim and Bennett, 1982).

The use of $\left[{ }^{125} \mathrm{I}\right]-\alpha$-BuTx rather than fluorescent toxin in our experiments allows quantitative assessment of the contribution of prelabeled AChRs to cluster formation. The results of the prelabeling experiment, considered alone, would suggest that most of the receptors present in the cluster arise by redistribution of pre-existing receptors. Thus, the density of labeled
AChRs in clusters on muscles that were prelabeled and cultured with nonradioactive toxin was $87 \%$ of that seen in control muscles that were labeled after culturing for 1 day. However, the examination of muscles that were cultured in labeled toxin revealed that the experimental situation was more complicated.

The total number of AChRs in muscles cultured in the presence of $\alpha$-BuTx is the sum of those that were present before culture at day 15 and those that appeared during the $22 \mathrm{hr}$ of culture. Each of these two populations was measured separately in the protocols that we used. Thus, receptors that were present at day 15 were measured by labeling with radioactive toxin and culturing with nonradioactive toxin $(15+1$, prelabeled), and receptors that were added later were measured by incubating briefly with nonradioactive toxin to block existing receptors and then culturing with radioactive toxin $(15+1$, postlabeled). When these two populations (Table I, lines 3 and 4) are summed, the total number of $\mathrm{AChRs}$ in muscles cultured with toxin is greater than the number of $\mathrm{AChRs}$ in muscles cultured without toxin $(15+1)$. This is true for both unclustered and clustered AChRs. Thus, the density of AChRs in the extrajunctional membrane on cells cultured with toxin was $392 / \mu \mathrm{m}^{2}$ and the density of those on control cells cultured without toxin was $243 / \mu \mathrm{m}^{2}$. The corresponding values for AChRs in clusters were 2364 and $1297 / \mu \mathrm{m}^{2}$, respectively. The total number of $\mathrm{AChRs}$ was thus $64 \%$ higher in muscles cultured with toxin than without it. In both normal and toxin-treated muscles, the density of AChRs at the endplate is comparable to that measured in vivo at 16 days of gestation (Bevan and Steinbach, 1977) but is well below that seen at junctions in adult rat muscle (Fambrough and Hartzell, 1972; Weinberg et al., 1981). Our experiments do not show whether the receptors that were inserted in the membrane during the culture period were added directly to the newly formed clusters (Bursztajn and Fischbach, 1980 ) or were added to the extrajunctional membrane and subsequently recruited into the cluster.

The increased number of $\mathrm{AChRs}$ in our experiments probably results from the continuous presence of $\alpha$-BuTx in the culture medium. As the nerves in these cultures are normally active (Ziskind-Conhaim and Dennis, 1981), the neuromuscular blockade produced by the toxin would cause a decrease in activity of the muscle fibers. Neuromuscular blockade has been shown to increase extrajunctional AChR density both in adult and in developing muscle fibers (Berg and Hall, 1975; Shainberg et al., 1976; Burden, 1977; Drachman et al., 1982), and the increased density of $\mathrm{AChRs}$ in the extrajunctional membrane could be responsible for the increased density of AChRs in the cluster. Thus, if extrajunctional AChRs are the major source of AChRs that form the cluster, as our results suggest, an increased number of precursors may hasten the growth in density of the cluster.

Our experiments clearly demonstrate that AChRs in the clusters formed in vitro at mammalian endplates arise in part by redistribution. They also show that continuous incubation in $\alpha$-BuTx can increase the rate of growth of these clusters.

\section{References}

Anderson, M. J., and M. W. Cohen (1977) Nerve-induced and spontaneous redistribution of acetylcholine receptors on cultured muscle cells. J. Physiol. (Lond.) 268: 757-770.

Anderson, M. J., M. W. Cohen and E. Zorychta (1977) Effects of innervation on the distribution of acetylcholine receptors on cultured muscle cells. J. Physiol. (Lond.) 268: 731-756.

Berg, D. K., and Z. W. Hall (1975) Increased extrajunctional acetylcholine sensitivity produced by chronic postsynaptic neuromuscular blockade. J. Physiol. (Lond.) 244: 659-676.

Bevan, S., and J. H. Steinbach (1977) The distribution of $\alpha$-bungaroxtoxin binding sites on mammalian skeletal muscle developing in vivo. J. Physiol. (Lond.) 267: 195-213.

Burden, S. (1977) Acetylcholine receptors at the neuromuscular junc- 
tion: Developmental change in receptor turnover. Dev. Biol. 61: 7985.

Bursztajn, S., and G. D. Fischbach (1980) Accumulation of coated vesicles bearing BTX binding sites in brain treated myotubes. Soc. Neurosci. Abstr. 6: 358

Christian, C. N., M. P. Daniels, H. Sugiyama, Z. Vogel, L. Jacques, and P. G. Nelson (1978) A factor from neurons increases the number of acetylcholine receptor aggregates on cultured muscle cells. Proc. Natl. Acad. Sci. U. S. A. 75: 4011-4015.

Dennis, M. J. (1981) Development of the neuromuscular junction: Inductive interactions between cells. Annu. Rev. Neurobiol. 4: 4368.

Dennis, M. J., L. Ziskind-Conhaim, and A. J. Harris (1981) Development of neuromuscular junctions in rat embryo. Dev. Biol. 81: 266279.

Devreotes, P. N., and D. M. Fambrough (1975) Acetylcholine receptor turnover in membranes of developing muscle fibers. J. Cell Biol. 65: 335-358.

Drachman, D. B., E. F. Stanley, A. Pestronk, J. W. Griffith, and D. L. Price (1982) Neurotrophic regulation of two properties of skeletal muscle by impulse-dependent and spontaneous acetylcholine transmission. J. Neurosci. 2: 232-244.

Fambrough, D. M., and H. C. Hartzell (1972) Acetylcholine receptors: Number and distribution at neuromuscular junctions in rat diaphragm. Science 176: 189-191.

Harris, A. J. (1981) Fmbryonic growth and innervation of rat skeletal muscles. Philos. Trans. R. Soc. Lond. 293: 257-314.

Harris, A. J., S. Heinemann, D. Schubert, and H. Tarakis (1971) Tropic interaction between cloned tissue culture lines of nerve and muscle. Nature 231: 296-301.

Kidokoro, Y. (1980) Developmental changes of spontaneous synaptic potential properties in the rat neuromuscular contact formed in culture. Dev. Biol. 78: 231-241.

Kidokoro, Y., and J. Patrick (1978) Correlation between miniature end-plate potential amplitude and acetylcholine receptor densities in the neuromuscular contact formed in vitro. Brain Res. 142: 368-373.

Reiness, C. G., and C. B. Weinberg (1981) Metabolic stabilization of acetylcholine receptors at newly formed neuromuscular junctions in rats. Dev. Biol. 84: 247-254.

Salpeter, M. M., S. Spanton, K. Holley, and T. R. Podleski (1982) Brain extract causes acetylcholine receptor redistribution which mimics some early events at developing neuromuscular junctions. $J$. Cell Biol. 93: 417-425.

Shainberg, A., S. A. Cohen, and P. G. Nelson (1976) Induction of acetylcholine receptors in muscle cultures. Pflugers Arch. 361: 255261.

Weinberg, C. B., J. R. Sanes, and Z. W. Hall (1981) Formation of the neuromuscular junctions in adult rats: Accumulation of acetylcholine receptors, acetylcholinesterase, and components of synaptic basal lamina. Dev. Biol. 84: 255-266.

Ziskind-Conhaim, L., and J. I. Bennett (1982) The effects of electrical inactivity and denervation on the distribution of acetylcholine receptors in developing rat muscle. Dev. Biol. 90: 185-197.

Ziskind-Conhaim, L., and M. J. Dennis (1981) Development of rat neuromuscular junctions in organ culture. Dev. Biol. 85: 243-251. 